\title{
WCC 2017-C-111: ANAMOLOUS ORIGIN OF RCA
}

\section{A. Siva Rama Krishna}

Adinarayanamma 66y of age diagnosed as CAD with NSTEMI, ECG shown ST depressions inferior leads 2d echo shows hypokinesia in RCA \& LAD territory \& mild lv systolic dysfunction.

CAG shown LAD distal 80\%, LCX Normal, RCA Anomalous origin from left sinus showing mid to distal $90 \%-96 \%$ lesion, distal vessel filling from the left segment.

RCA was engaged with 6f EBU 3.0 lesion was crossed with PILOT50 $0.014^{*} 190 \mathrm{~cm}$, Pre dilated with $1.5^{*} 8 \mathrm{~mm}$ \& 2. ${ }^{*} 12 \mathrm{~mm}$, scented with indolimus $2.5^{*} 36$ (DES) Post dilatation $2.5^{*} 12 \mathrm{~mm}$ Post stenting TIMI II flow acquired.

CAG
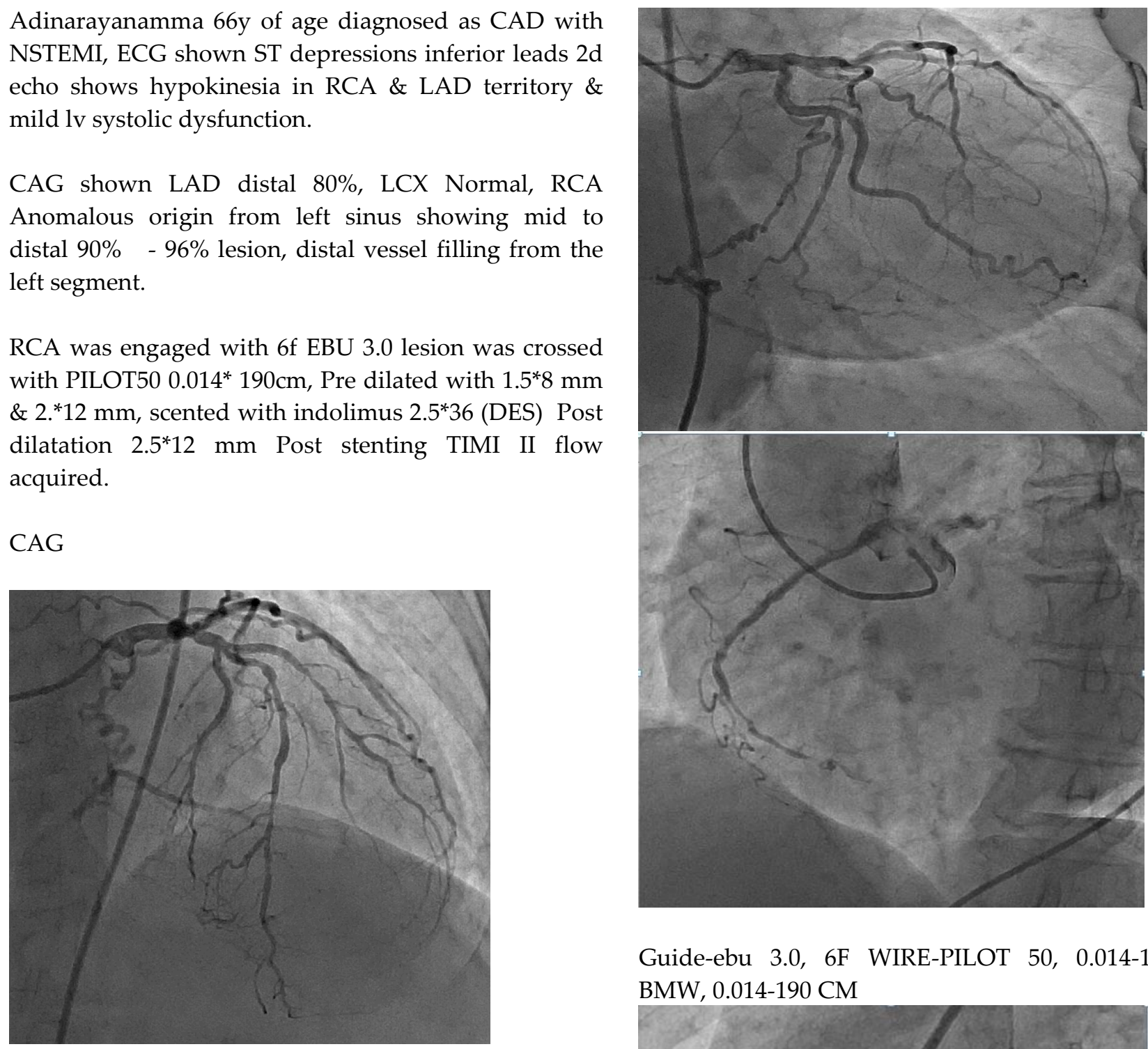

Guide-ebu 3.0, 6F WIRE-PILOT 50, 0.014-190 CM BMW, 0.014-190 CM

Article received on 25 FEB 2017, published on 08 MAR 2017.

${ }^{1}$ Assistant Professor, Department of Cardiology, Guntur Medical College, India Corresponding Author: A. Siva Rama Krishna

Email: drsrkarikeri@gmail.com

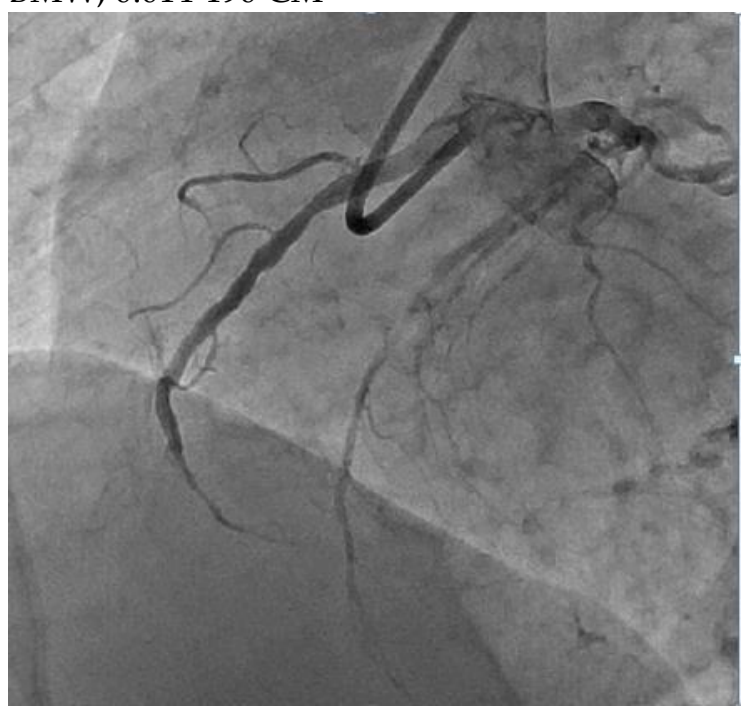




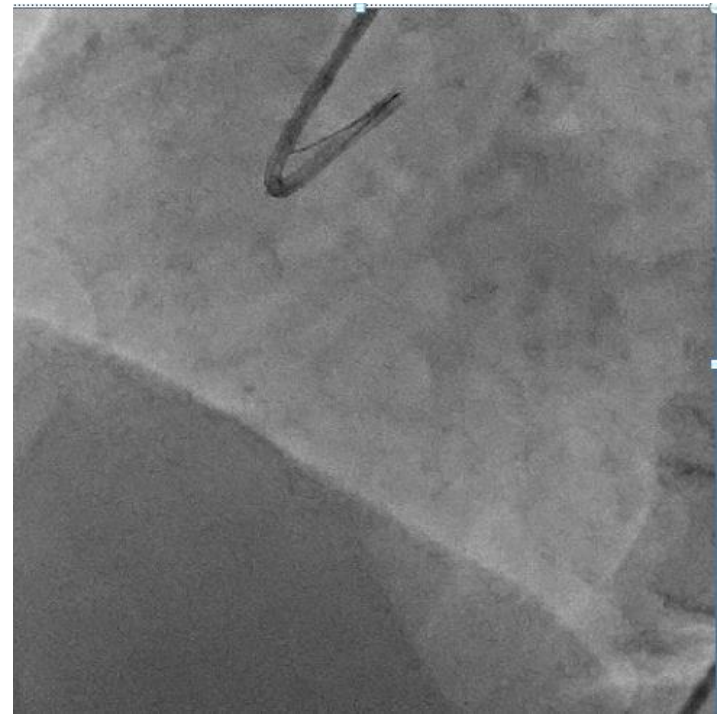

PREDILATATION-1.5*8mm2*12mm

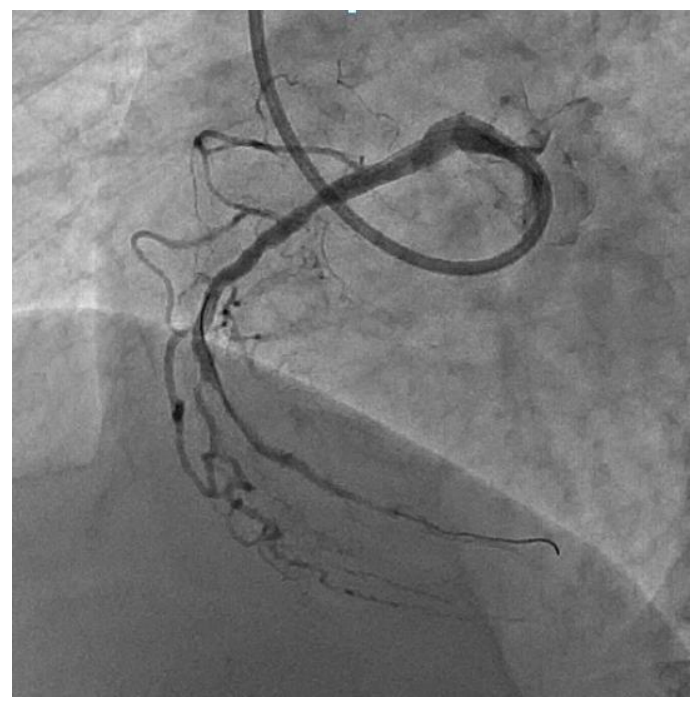

Indolimus $-2.5^{*} 36 \mathrm{~mm}$

Post dilatation-NC TREK $2.5^{*} 12 \mathrm{~mm}$
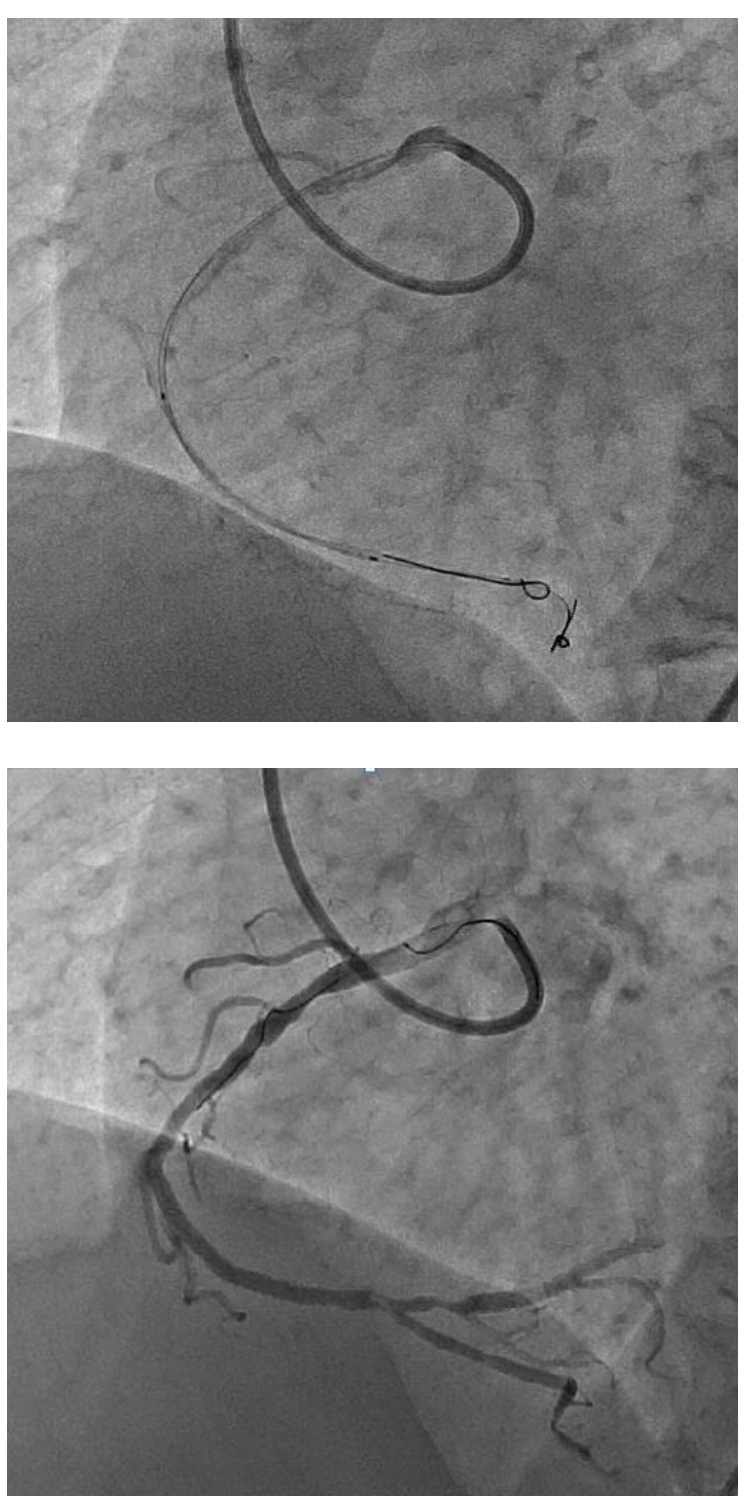